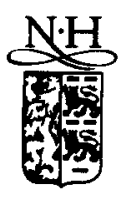

ELSEVIER

Applied Surface Science 92 (1996) 208-211

\title{
Rapid thermal post-metallization annealing effect on thin gate oxides
}

\author{
Ming-Jer Jeng * , Huang-Shen Lin, Jenn-Gwo Hwu \\ Department of Electrical Engineering, Room 446, National Taiwan University, Taipei, Taiwan, ROC
}

Received 12 December 1994; accepted for publication 28 May 1995

\begin{abstract}
Rapid thermal processing is used for post-metallization annealing (PMA) in this work. It was found that the rapid thermal PMA can do almost the same anneal work in the initial characteristics of MOS capacitors with an oxide thickness of $10 \mathrm{~nm}$ as the conventional furnace PMA. But the reliabilities in hot-carrier and radiation resistances of MOS capacitors depend on the PMA process significantly. It was found that rapid thermal PMA samples exhibit worse properties in hot-carrier resistance but better properties in radiation hardness than furnace PMA samples. For rapid thermal PMA process, the higher the annealing temperature, the stronger the initial annealing extent but the worse the hot-carrier and the radiation resistances.
\end{abstract}

\section{Introduction}

High quality thin oxide devices are necessary in VLSI technology. Many works had been done on how to grow high quality oxide layer, such as nitride oxides [1], reoxided nitrided oxides [2,3], or $\mathrm{N}_{2} \mathrm{O}$ oxides [4,5], etc. In addition, a few works [6,7] reported that the post-metallization annealing (PMA) process can also affect the performance of MOS devices. It is well known that the PMA is necessary for devices after metallization process. It can sinter the metal/silicon contact and lower the contact resistance. In addition, it can also anneal the defects at the interface, such as fixed oxide charges, oxide trapped charges and interface charges. Recently, rapid thermal processing is widely used in IC technology $[1,2,6-8]$. Mainly, it can reduce some drawbacks

\footnotetext{
- Corresponding author. Tel.: + $8862363-5251-446$.
}

caused by conventional furnace processing, such as long duration and out-diffusion, etc. It is believed that rapid thermal processing is also applicable to PMA. It is known that the samples with poly-gates may show quite different behavior from those with metal-gates [8]. For simplicity, only poly-gate MOS capacitors are investigated in this work. It is found that the rapid thermal PMA can achieve almost the same annealing effect as the furnace PMA. In addition, it was found that an annealing temperature of $500^{\circ} \mathrm{C}$ in rapid thermal PMA is high enough to effectively reduce the oxide defects. However, it is noted that the sample with a low annealing temperature is more resistant to hot carrier stress and radiation damage than the one with a high annealing temperature. The same phenomenon is also observed in furnace PMA samples. Possible mechanisms are given for these phenomena based on the bond-strain gradient model $[9,10]$. 


\section{Sample preparations}

The sample substrates are p-type $\mathrm{Si}(100) 3^{\prime \prime}$ wafers with a resistivity of $\sim 20-50 \Omega \cdot \mathrm{cm}$. They were oxidized in dry $\mathrm{O}_{2}$ at $980^{\circ} \mathrm{C}$ and then in situ annealed in $\mathrm{N}_{2}$ for 10 min to obtain a thickness of about $10 \mathrm{~nm}$. A LPCVD poly-Si film with a thickness of about $300 \mathrm{~nm}$ was deposited at $620^{\circ} \mathrm{C}$. The deposition pressure and the deposition rate are $\sim 180-220 \mathrm{mTorr}$ and $10 \mathrm{~nm} / \mathrm{min}$, respectively. Doping of the poly-Si films was achieved by $\mathrm{POCl}_{3}$ diffusion at $950^{\circ} \mathrm{C}$ for $20 \mathrm{~min}$. After removing the phospho-oxide, Al-gate films with a thickness of 90 nm were thermally evaporated and then patterned by photolithography method. Finally, after removing the backside poly-Si film and oxide, Al films were also evaporated on the backside for electrical contacts. Various PMA processes were then carried out after sample preparation. The flatband voltage $V_{\mathrm{FB}}$ and midgap interface trap density $D_{\text {itm }}$ are obtained from high-low frequency $C-V$ curves. Hot-carrier stress was performed with a constant current density of $J=0.1 \mathrm{~mA} / \mathrm{cm}^{2}$ for $10 \mathrm{~s} .{ }^{60} \mathrm{Co}$ irradiations with a total dose of $1 \mathrm{Mrad}$ were performed to examine the radiation hardness. Time zero dielectric breakdown TZDB characteristics were obtained by applying a staircase voltage of $\mathrm{d} V_{\mathrm{G}} / \mathrm{d} t=0.5 \mathrm{~V} / \mathrm{s}$ on samples until a current of $1 \mu \mathrm{A}$ was reached.

\section{Results and discussion}

Fig. 1a shows the $C-V$ curves of MOS capacitors before and after various rapid thermal PMAs with annealing temperatures of 400,450 and $500^{\circ} \mathrm{C}$, a temperature rising rate of $700^{\circ} \mathrm{C} / \mathrm{min}$ and a holding time of $30 \mathrm{~s}$. Clearly, the higher the annealing temperature, the larger the annealing effect, i.e. more significant reduction of the oxide charges and interface trap charges. The annealing temperature of $400^{\circ} \mathrm{C}$ in rapid thermal PMA seems to be not high enough to anneal out the oxide defects. Thus, from the viewpoint of annealing effect, an annealing temperature of $500^{\circ} \mathrm{C}$ is suggested for rapid thermal PMA. In addition, the $C-V$ curves of MOS capacitors before and after furnace PMA with annealing temperatures of 400 and $450^{\circ} \mathrm{C}$ and an annealing

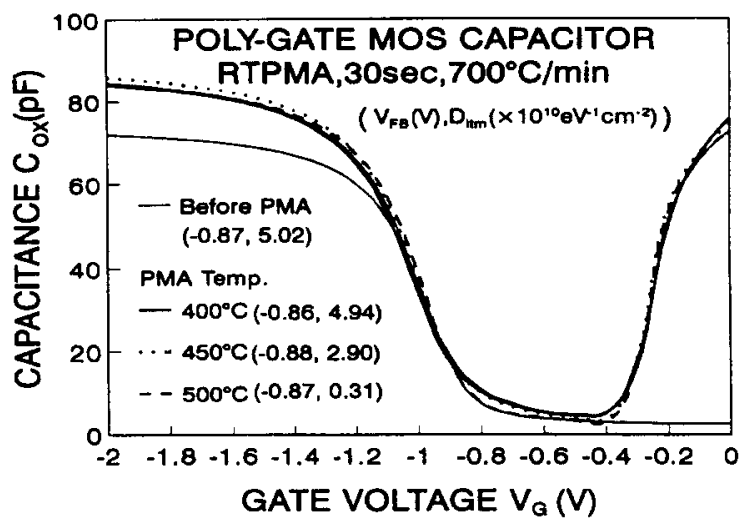

(a)

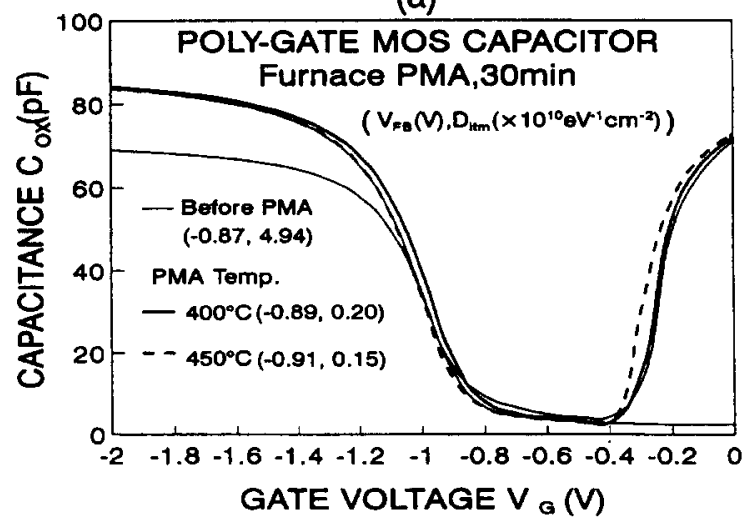

(b)

Fig. 1. $C-V$ curves of MOS capacitors before and (a) after various rapid thermal PMAs with annealing temperatures of 400 , 450 and $500^{\circ} \mathrm{C}$, a temperature rising rate of $700^{\circ} \mathrm{C} / \mathrm{min}$ and a holding time of $30 \mathrm{~s}$ and (b) after various fumace PMAs with annealing temperatures of 400 and $450^{\circ} \mathrm{C}$ and an annealing time of $30 \mathrm{~min}$.

time of $30 \mathrm{~min}$ is shown in Fig. 1b. Although the annealing temperature is 400 or $450^{\circ} \mathrm{C}$, the long time annealing results in quite large reduction in oxide defects. From Figs. $1 \mathrm{a}$ and $1 \mathrm{~b}$, it can be seen that the rapid thermal PMA with an annealing temperature of $500^{\circ} \mathrm{C}$ and a holding time of $30 \mathrm{~s}$ provides the same annealing effect as the furnace PMA with an annealing temperature of $450^{\circ} \mathrm{C}$ and an annealing time of $30 \mathrm{~min}$. Therefore, the PMA by rapid thermal heater can save much more processing time than using a conventional furnace.

Fig. 2a shows the $C-V$ curves of MOS capacitors with various rapid thermal PMAs before and after a constant current stress (gate biased negatively) of 


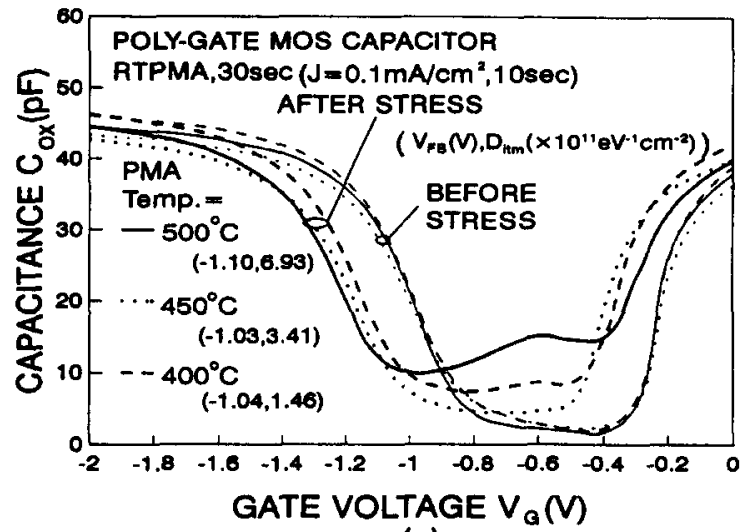

(a)

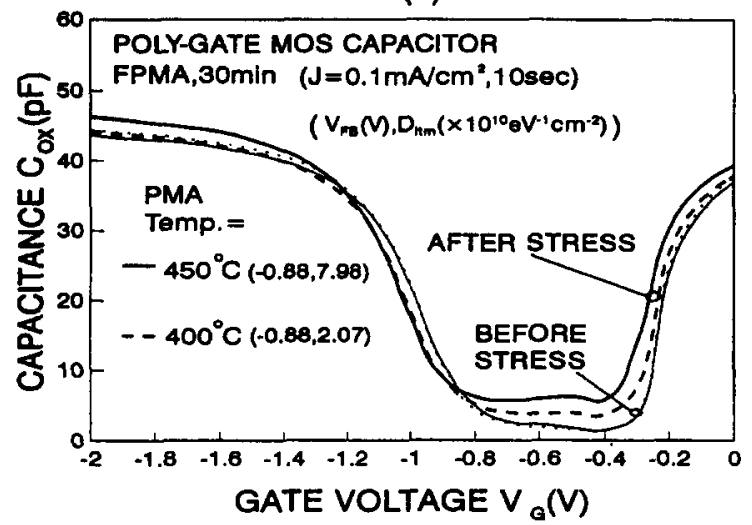

(b)

Fig. 2. $C-V$ curves of MOS capacitors with (a) various rapid thermal PMAs and (b) various furnace PMAs before and after a constant current stress of $J=0.1 \mathrm{~mA} / \mathrm{cm}^{2}$ for $10 \mathrm{~s}$.

$J=0.1 \mathrm{~mA} / \mathrm{cm}^{2}$ for $10 \mathrm{~s}$. The gate voltage during stress for all samples is about $-11 \mathrm{~V}$. It is noted that positive oxide charges were built up in the MOS capacitors after constant current stresses, i.e. $V_{\mathrm{FB}}$ is more negative after stresses. Clearly, the sample with an annealing temperature of $400^{\circ} \mathrm{C}$ exhibits smaller stress-induced oxide charges and interface trap charges than the ones with 450 and $500^{\circ} \mathrm{C}$. It is interesting to note that the poorer the initial annealing effect, the better the resistance to constant current stress. It is possibly due to the reason that the oxide with a poor initial PMA may have many unsatisfied bonds near the $\mathrm{SiO}_{2} / \mathrm{Si}$ interface. In such case, the interfacial strain is small which in turn results in a better hot-carrier resistance. The $C-V$ curves of MOS capacitors with various furnace PMAs before and after a constant current stress of $J=0.1$
$\mathrm{mA} / \mathrm{cm}^{2}$ for $10 \mathrm{~s}$ are shown in Fig. $2 \mathrm{~b}$. It is noted that the sample with an annealing temperature of $400^{\circ} \mathrm{C}$ also exhibits smaller stress-induced oxide charges and interface trap charge than the one with an annealing temperature of $450^{\circ} \mathrm{C}$.

Figs. $3 \mathrm{a}$ and $3 \mathrm{~b}$ show the $C-V$ curves of MOS capacitors with various rapid thermal and furnace PMAs before and after 1 Mrad ${ }^{60} \mathrm{Co}$ irradiations. It can be seen that the behavior of the radiation-induced oxide charges and interface trap charges is similar to that observed in Fig. 2. That is to say, the poorer the initial PMA, the smaller the interfacial strain, and therefore the better the radiation hardness. It is noted from Figs. $3 a$ and $3 b$ that the rapid thermal PMA samples are more radiation hard than the furnace PMA samples although their constant

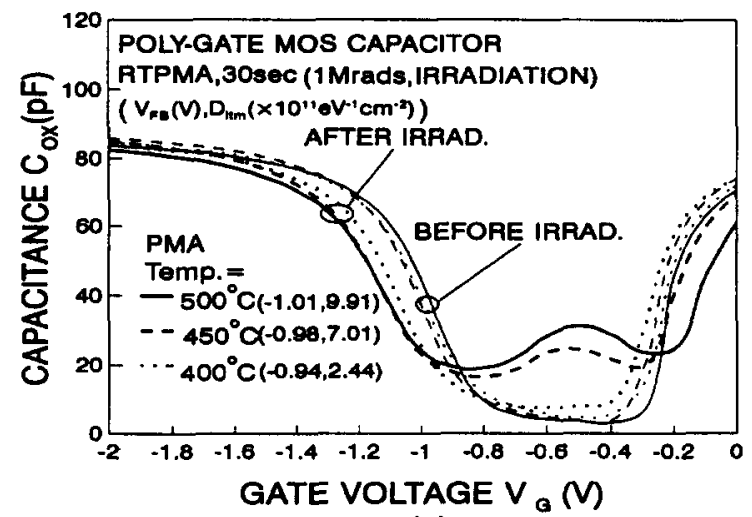

(a)

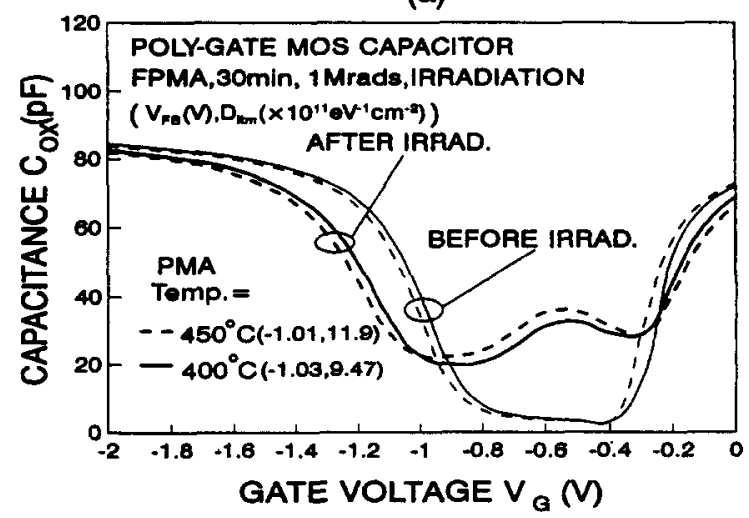

(b)

Fig. 3. $C-V$ curves of MOS capacitors with (a) various rapid thermal PMAs and (b) various fumace PMAs before and after 1 Mrad ${ }^{60} \mathrm{Co}$ irradiations. 


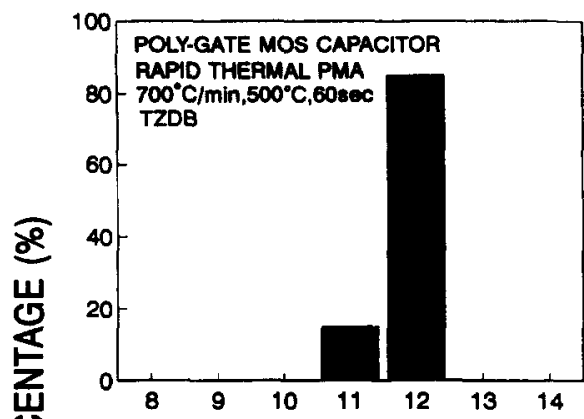

(a)

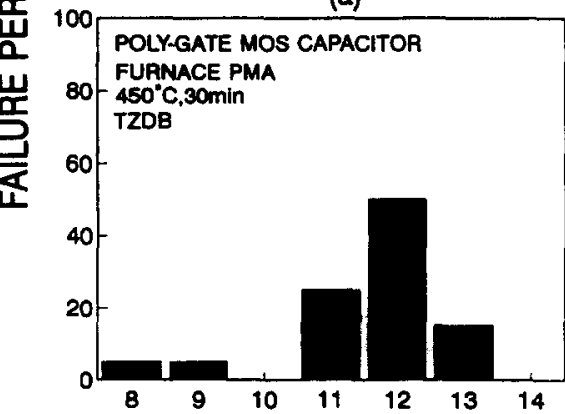

(b)

\section{BREAKDOWN FIELD $E_{B D}(\mathrm{MV} / \mathrm{cm})$}

Fig. 4. Time-zero dielectric breakdown (TZDB) distributions of breakdown field $E_{\mathrm{BD}}$ of MOS capacitors with (a) various rapid thermal PMAs and (b) various furnace PMAs.

current stress behavior is opposite to that observed in Figs. $2 a$ and $2 b$.

Figs. $4 a$ and $4 b$ show the time-zero dielectric breakdown (TZDB) distributions of breakdown field $E_{\mathrm{BD}}$ of MOS capacitors with various rapid thermal and furnace PMAs, respectively. Clearly, the MOS capacitors with rapid thermal PMAs have better reliability performance than those with furnace PMAs. It is noted that aluminum may penetrate through poly-Si into the $\mathrm{SiO}_{2}$ layers during the long time annealing in furnace PMA. The local electrical field may be enhanced during breakdown measurement and therefore results in poor dielectric breakdown.

\section{Conclusion}

In this work, it is found that rapid thermal PMA with a temperature of $500^{\circ} \mathrm{C}$ for $30 \mathrm{~s}$ can effectively reduce the oxide charges and interface trap charges. Much time can be saved by using rapid thermal PMA with respect to furnace PMA. It is also found that samples with a low temperature annealing are more resistant to hot carrier stress and radiation damage than those with a high temperature annealing. Finally, it is suggested that suitable choices of the (short) time and (high) temperature in rapid thermal PMA can result in good reliability performance for thin oxide MOS devices.

\section{Acknowledgement}

The authors would like to thank the National Science Council of the Republic of China for supporting this work under contract No. NSC-84-2215E-002-006.

\section{References}

[1] T. Hori, H. Iwasaki, Y. Naito and H. Esaki, IEEE Trans. Electron Devices ED-34 (1987) 2238.

[2] T. Hori, H. Iwaski and K. Tsuji, IEEE Trans. Electron Devices ED-36 (1989) 340.

[3] B.S. Doyle and G.J. Dunn, IEEE Electron Device Lett. EDL-13 (1992) 38.

[4] J. Ahn, A. Joshi, G.Q. Lo and D.L. Kwong, IEEE Electron Device Lett. EDL-13 (1992) 513.

[5] J.C. Chen, Z. Liu, J.T. Krick, P.K. Ko and C. Hu, IEEE Electron Device Lett. EDL-14 (1993) 225.

[6] P. Lundgren, M.O. Anderson and K.R. Farmer, J. Appl. Phys. 74 (1993) 4780.

[7] C.S. Pai, E. Cabreros, S.S. Lau, T.E. Seidel and I. Suni, Appl. Phys. Lett. 46 (1985) 652.

[8] M.L. Reed and J.D. Plummer, J. Appl. Phys. 63 (1988) 5776.

[9] F.J. Grunthaner, B.F. Lewis, N. Zamini and J. Maserjian, IEEE Trans. Nucl. Sci. NS-27 (1980) 1640.

[10] F.J. Grunthaner, P.J. Grunthaner and J. Maserjian, IEEE Trans. Nucl. Sci. NS-29 (1982) 1462. 